\title{
INHERITANCE OF IMMUNITY TO MILDEW IN PERUVIAN FORMS OF PISUM SATIVUM
}

\author{
S. C. HARLAND \\ Institute of Cotton Genetics, National Agricultural Society, Lima, Peru
}

\section{INTRODUCTION}

Received 28.i.48

When the Spaniards settled in Peru during the sixteenth and subsequent centuries they introduced many domesticated plants and animals, which initially were adapted to south European conditions, and which have now become adapted to the high altitudes of the Andes. The Andean region may thus be regarded as an important secondary centre of diversity of such crops as wheat, barley, peas, alfalfa, broad beans, etc. These exist as "land races," showing much heterogeneity in respect of both morphological and physiological characters. Part of the heterogeneity is due to the fact that little or no selection has ever been practised with these crops; part is perhaps due to four hundred years of isolation in a new environment, providing an opportunity not only for new systems of gene frequencies to become established, but also for new mutations and combinations of mutations of ecological value to be tested. In the case of Pisum sativum L., part of the heterogeneity is certainly due to a change in the breeding system, whereby a previously self-pollinated plant becomes fairly frequently cross-pollinated in an environment with new insect visitors.

In I943 the writer collected a sample of locally grown peas in Huancabamba, a small town in the Andes of northern Peru, which until quite recently was so isolated that a journey of several days by mule was required to reach it from the coastal town of Piura. Huancabamba is situated at an altitude of 639 I feet above sea-level (Lat. S. $5^{\circ}$ I $5^{\prime}$, Long. W. $79^{\circ} 30^{\prime}$ ) in the middle of a typically temperate climate agriculture. The principal crops of the region are maize, barley, potatoes, alfalfa, peas, and beans (Faba vulgaris L.).

The Huancabamba peas sown in the genetics garden in Lima were for the most part attacked violently by the mildew, Erysiphe polygoni D.G., which, except in the middle of the cold season, is a limiting factor in the cultivation of this crop on the coast. About Io per cent. of the plants, however, were completely immune to mildew, and at no time showed the slightest trace of infection.

This paper gives an account of the mode of inheritance of immunity, and of the linkage relationship of the gene for immunity to flower colour, in crosses with the susceptible variety First of All. 


\section{THE EXPERIMENTAL RESULTS}

The cross

Flower colour

Axil

Maturity

Mildew reaction

First flower
HuAncabamba $\times$ First of AlL purple pigmented late immune white unpigmented early susceptible

$\mathrm{F}_{1}$ : All plants were severely attacked by mildew.

$\mathrm{F}_{2}$ : Two families were grown with results which are given in table $\mathbf{I}$.

TABLE I

Segregation for immunity to mildew in the $F_{2}$ of the cross Huancabamba immune $\times$ FIRST OF ALL susceptible

\begin{tabular}{|c|c|c|}
\hline Family & Susceptible & Immune \\
\hline A 7-1. & 95 & 29 \\
\hline A 8-2. & 83 & 33 \\
\hline Total & 178 & 62 \\
\hline Expected & 180 & 60 \\
\hline
\end{tabular}

Segregation was clear, there being no trace of infection in the immunes. It thus appears that immunity is due to a single genetical difference. The $\mathrm{F}_{3}$ results are presented in table 2 .

TABLE 2

$F_{3}$ results of the cross HUANCABAMBa $\times$ First OF ALL

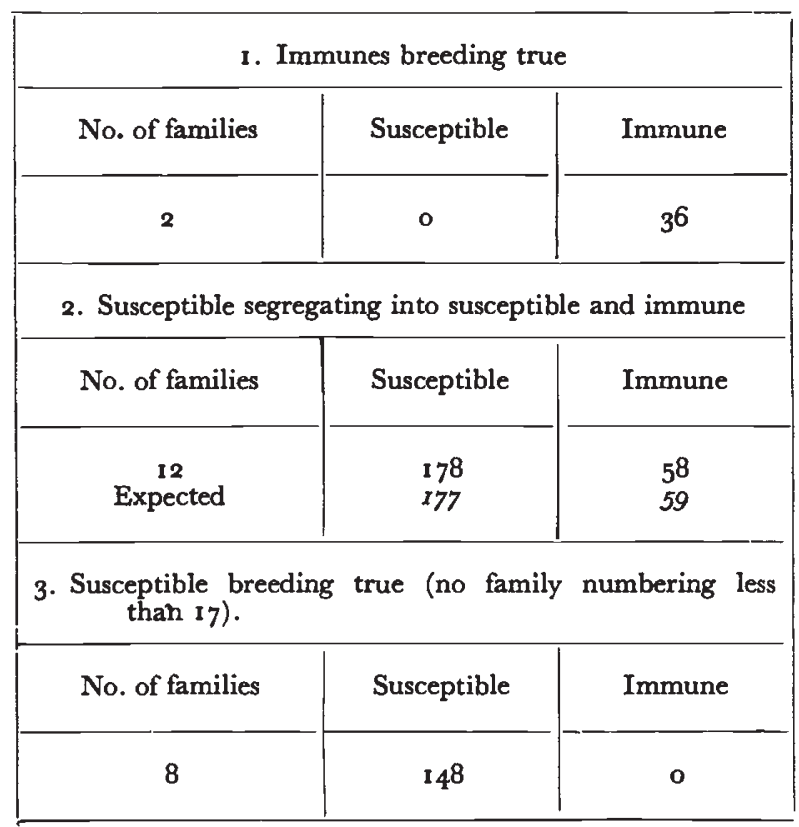


The ratio of heterozygous to homozygous families was $12: 8$, with expectation $13.3: 6 \cdot 6$. It is thus clear that immunity to mildew is inherited as a simple Mendelian recessive.

Hammarlund (1925) found immunity to mildew in peas in Sweden. Segregation in $F_{2}$ gave 475 susceptible and 3 immunes. $\mathrm{He}$ thought that four cumulative factors were involved in building up susceptibility. He called the mildew Erysiphe communis. It is not known whether the organism worked with by Hammarlund is the same as that discussed in this paper.

\section{THE $F_{4}$ NATURAL CROSSING}

The $F_{4}$ results confirmed those obtained in previous generations. Immune continued to breed true in $F_{4}$ in 18 families with a total of 397 plants. Three families which should have bred true gave small numbers of susceptibles, viz. :-

\begin{tabular}{|c|c|c|}
\hline Family & Susceptible & Immune \\
\hline $\begin{array}{l}\text { A 8-2-9-10 } \\
\text { A 8-2-1 2-6: } \\
\text { A 8-2-4r-5: }\end{array}$ & $\begin{array}{l}3 \\
9 \\
3\end{array}$ & $\begin{array}{l}17 \\
11 \\
17\end{array}$ \\
\hline
\end{tabular}

These were suspected to be due to crossing with neighbours. The results were re-examined to see if families with recessive white parents also gave crosses. It was found that out of $3 \mathrm{I} \mathrm{F}_{4}$ families from $F_{3}$ whites, 21 bred true, giving 336 plants. Ten families, however, threw a varying number of purple crosses, ig with purple flowers to I 5 I with white flowers.

Thus out of 506 expected white plants 19 were undoubted vicinists or contaminants indicating about 3.9 per cent. of natural crossing. Using the data from the susceptible vicinists in expected homozygous immunes the number of vicinists is 15 out of 457 or 3.3 per cent.

In the family A 8-2-12-16, the parent of which was an immune white with a node number of 10 , it was possible to state with certainty that of 20 plants, 12 were vicinists.

The insect responsible for natural crossing is the large black carpenter bee, Xylocopa sp. It was not seen visiting the $\mathbf{F}_{1}$ or $\mathbf{F}_{2}$ cultures, but was seen visiting the $F_{3}$, though not in great numbers. The same insect produced so much natural crossing in sweet peas (Lathyrus) that all flowers used for genetical purposes had to be covered. The same, or a similar insect was responsible for much contamination in the writer's genetical experiments with cowpeas in the West Indies (Harland, I919). In Trinidad, Xylocopa works the flowers of the French bean (Phaseolus vulgaris L.), but the weight of the insect is so great that the stigmas are broken (so Professor K. S. Dodds tells me), thus rendering the plants more or less sterile. 
It is possible that in the pea growing districts Xylocopa might be much more abundant than in the small city garden where the experiments were conducted and natural crossing more frequent.

In Europe, and in other regions where Pisum has been bred experimentally, contamination is so rare that it is unnecessary to protect the flowers. Nothing is known of natural crossing in what is thought to be the centre of origin (Abyssinia), but the re-transference of Pisum to the Tropics, where it meets with new insects, has converted it (or re-converted it) from a plant hitherto regarded as a typical example of obligatory self-fertilisation to one which may undergo a considerable amount of natural crossing.

\section{LINKAGE OF PURPLE FLOWER AND IMMUNITY}

Evidence of linkage between $A$ (purple flower and pigmented axil) and $E r$ (susceptible) was obtained in the $\mathrm{F}_{2}$ and confirmed by the results of $F_{3}$.

Inspection of the data was sufficient to show that the two genes were linked in the repulsion phase. Linkage values were calculated by Fisher's product method, using the tables given by Immer (1930).

Results of $F_{2}$

\begin{tabular}{|l|l|l|l|l|l|c|}
\hline & \multicolumn{1}{|c|}{$A$ Er } & \multicolumn{1}{|c|}{$A$ er } & a Er & a er & $\chi_{[2]}^{2}$ & $P$ \\
\hline Observed . & 142 & 57 & $3^{6}$ & 5 & $\ldots$ & $\ldots$ \\
\hline Expected . & $127 \cdot 49$ & $5^{2 \cdot 51}$ & $5^{2 \cdot 51}$ & $7 \cdot 49$ & $8 \cdot 054$ & $0 \cdot 02-0 \cdot 01$ \\
\hline
\end{tabular}

The expected values were calculated using the recombination percentage of 35.3 found from these data. The fit with observation is still not good, but the discrepancies are due solely to the poor agreement of the $A-a$ segregation with the expected $3: \mathrm{I}$.

Results of $F_{3}$. Ten families numbered

\begin{tabular}{|c|c|c|c|c|c|}
\hline$A$ Er & A er & a Er & a er & $\chi_{[2]}^{2}$ & $P$ \\
\hline 103 & 44 & 34 & 5 & $\ldots$ & $\ldots$ \\
\hline $98 \cdot 77$ & $40 \cdot 73$ & $40 \cdot 73$ & $5 \cdot 77$ & $1 \cdot 659$ & $0.5-0.3$ \\
\hline
\end{tabular}

These data give a recombination percentage, $35^{\circ}$, in good agreement with that of $\mathrm{F}_{2}$. The segregation of $A$ - $a$ is better and $\chi^{2}{ }_{[2]}$ shows satisfactory agreement of the observed frequencies with those expected on this linkage value. 


\section{LINKAGE OF PURPLE FLOWER AND NODE NUMBER}

Pellew (1927, 1940) states that differences in node number, i.e. the node at which the first flower is produced, are genetically determined by a series of three multiple alleles as follows :-

$$
\begin{aligned}
& L \text { Ist flower at about the I } 8 \text { th node } \\
& l_{1}, \quad, \quad, \quad, \quad, \quad \text { I } 5^{\text {th }}, \\
& l_{2}, ", \quad, \quad, \quad, \quad 9 \text { th },
\end{aligned}
$$

She states that there is a well-established linkage between $A$, basic gene for anthocyanin colour of flower, and the $L$ series of multiple alleles, with about i 2 per cent. recombination.

In these experiments the existence of linkage has been confirmed. The results for a series of $F_{3}$ families giving clear segregation are given in table 3. There is some variation both within and between families in the node number at which the first flower appears; but the segregation is nevertheless clear in each family.

\section{RELATIONSHIP BETWEEN NODE NUMBER AND

\begin{tabular}{|c|c|c|c|c|c|}
\hline & & $L E r$ & Ler & $l E r$ & ler \\
\hline Expected & . & $6 \mathrm{I}$ & 27 & $2 \pi$ & 7 \\
\hline $9: 3: 3: 1$ & . $\quad$. & $65 \cdot 25$ & $2 r \cdot 75$ & $2 r \cdot 75$ & $7 \cdot 25$ \\
\hline
\end{tabular} IMMUNITY TO MILDEW}

In $\operatorname{six} \mathrm{F}_{\mathbf{3}}$ families the results were :-

It is clear that there is no evidence of linkage between $L$ and $E r$.

\section{ORDER OF THE GENES ON THE A CHROMOSOME}

The order of the genes must be :-

$$
\begin{array}{lllll}
L & \text { I2.0 } & A & 35 \cdot 3 & E r
\end{array}
$$

\section{DISCUSSION}

Here in a secondary centre of diversity of Pisum sativum a gene has been encountered which confers complete immunity to the Peruvian variety or race of mildew, presumably a race of Erysiphe polygoni D.C. It is not yet known whether any other races of Erysiphe exist to which the present immune Pisum is susceptible, and it is necessary to see whether immunity is kept when grown in Europe and North America.

Should the immunity be conserved, it could easily be transferred to all present commercial varieties by the well-known technique of repeated back-crossing and selfing. 
S. C. HARLAND

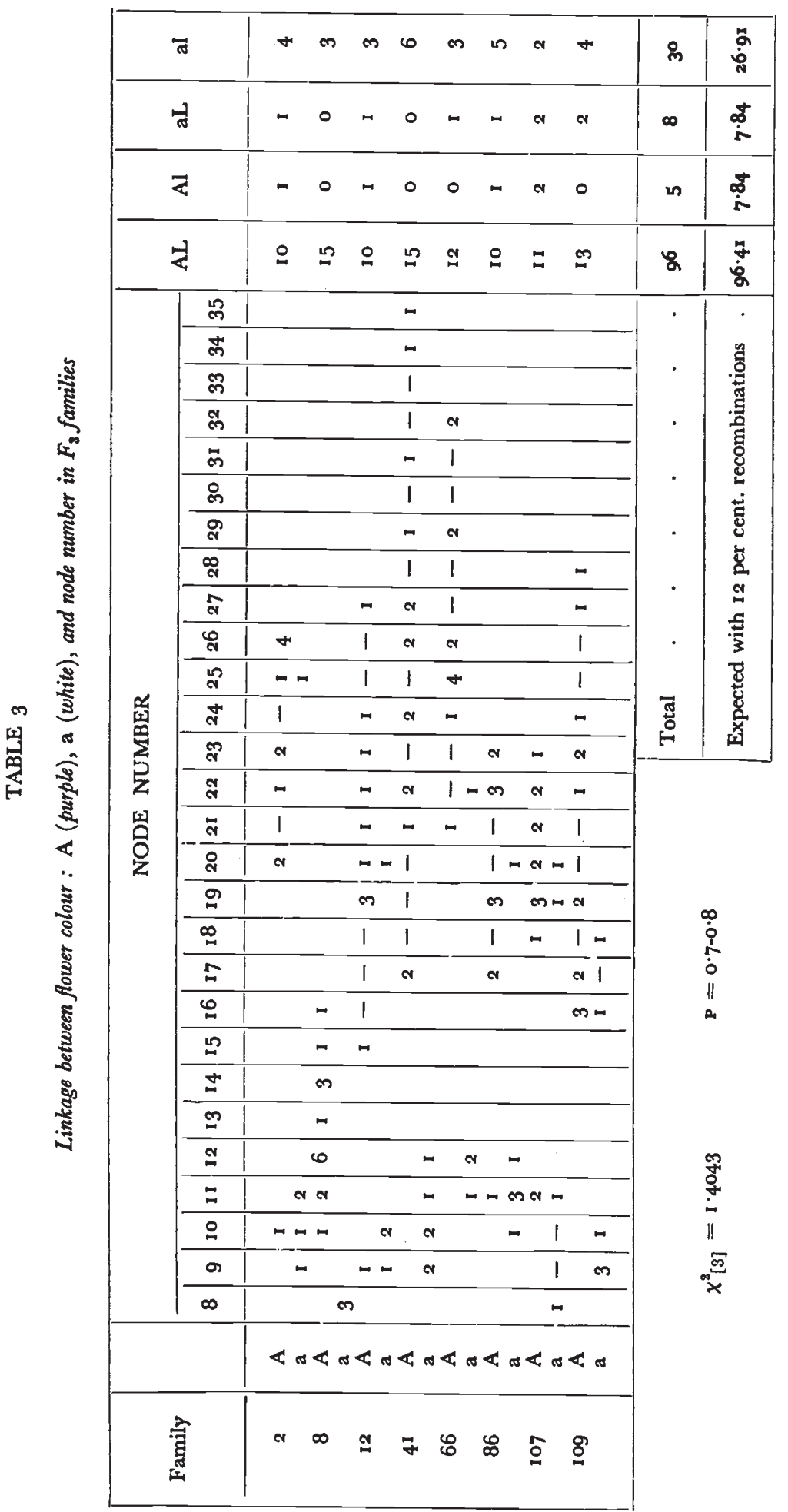


The second point of importance is that there has been a change in the breeding system of Pisum, due to a change in the associated insect fauna. A plant which is normally self-fertilised now becomes subject to natural crossing. This change in the breeding system, which can be paralleled by other plants, e.g. tomato, which in their native homes are extensively crossed and in Europe are regarded as typically self-fertilised plants, is of importance. New genes of slight advantage can diffuse throughout the breeding population at a fairly rapid rate, bringing the Fisher mechanism of dominance attainment into play. It is likely that this change may influence the potency of genes affecting dominance. Where self-fertilisation is the rule dominance appears to be more often secured by genes of great dominance potency (Haldane, I930; Harland and Atteck, I94I), whereas in a cross-fertilised plant dominance is often likely to be secured by a system or constellation of modifiers which elevate an intermediate heterozygote towards full dominance. It is thus not without significance that the inheritance of disease resistance has proved simpler in barley and wheat than in maize.

\section{SUMMARY}

I. Susceptibility to mildew (Erysiphe polygoni) in a Peruvian form of Pisum sativum is governed by a single gene. Susceptibility-immunity Er-er.

2. There is linkage between the gene for susceptibility and the anthocyanin factor $A$ of the order of 35 units.

3. There is linkage between the node number series of alleles (the $L$ series of Pellew ( $l$ c.c.)) and the anthocyanin factor $A$ of the order of 12 units.

4. The order of genes on the $A$ chromosome is $L \ldots A$. Er.

5. Pisum in Peru is a partially cross-fertilised plant. Some consequences of the change in the breeding system are discussed.

Acknowledgments.-I am greatly indebted to Miss Gabryela M. Kermenić for help in these experiments which she was almost entirely responsible for planting and recording. I am also grateful to $\mathrm{Dr} \mathrm{K}$. Mather for necessary emendations in the manuscript.

\section{REFERENCES}

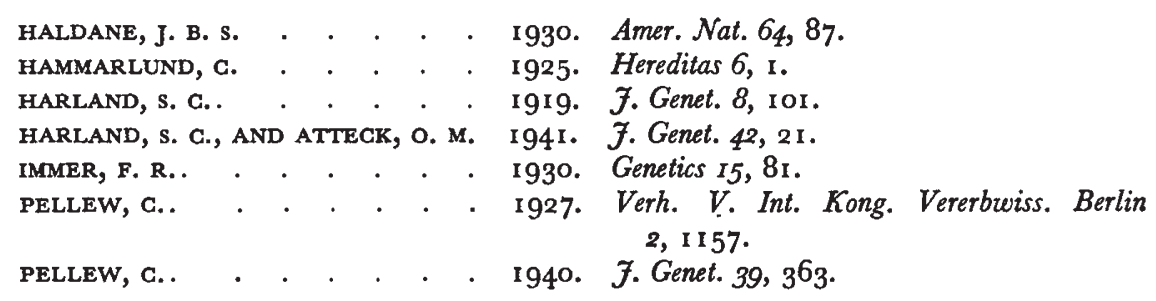

